\title{
Activation of the G-protein-coupled receptor GPR30 induces anxiogenic effects in mice, similar to oestradiol
}

\author{
Iris Kastenberger • Christian Lutsch • \\ Christoph Schwarzer
}

Received: 7 July 2011 / Accepted: 21 November 2011 /Published online: 7 December 2011

(C) The Author(s) 2011. This article is published with open access at Springerlink.com

\begin{abstract}
Rationale The influence of ovarian hormones on behaviour is well accepted, and oestrogen replacement therapy has proven to be beneficial in several cases of menopausal mood disorders. However, there are also some adverse effects of such a therapy, like anxiety and dysphoria. In fact, some women feel better at low levels of oestrogen and worse when levels fluctuate. Still, it is unclear which receptors might mediate negative emotional effects.

Objectives The aim of this study was to identify which oestrogen receptor(s) are capable of mediating negative emotional effects and, therefore, may represent candidates responsible for the adverse side effects observed in oestrogen replacement therapy.

Results We provide evidence from mouse behavioural tests that oestrogen-induced anxiogenic-like effects might be mediated, at least in part, by the $\mathrm{G}$ protein-coupled receptor GPR30. The short-term application of specific agonists against the alpha and beta oestrogen receptors did not result in marked behavioural changes. In contrast, the specific stimulation of GPR30 in male and ovariectomized female mice induced anxiogenic effects. The anxiogenic effects induced by the specific GPR30 agonist G-1 were comparable (and non-accumulative) to those observed after low doses of the general oestrogen receptor agonist 17b-oestradiol in male mice, thereby reflecting the behavioural changes observed in intact female mice during early pro-oestrus. Conclusions Our data suggest that GPR30 induces acute anxiogenic effects of oestrogen in rodents. It is tempting to speculate that a potential imbalance in the expression of the anxiolytic beta oestrogen receptor and the anxiogenic
\end{abstract}

I. Kastenberger $\cdot$ C. Lutsch $\cdot$ C. Schwarzer $(\bowtie)$

Department of Pharmacology, Innsbruck Medical University,

Peter-Mayr-Str. 1a,

6020 Innsbruck, Austria

e-mail: schwarzer.christoph@i-med.ac.at
GPR30 may also be involved in the negative symptoms of oestrogen replacement therapy in humans.

Keywords Emotional control · G-protein-coupled receptor . Oestrous cycle · Ovarian steroids · Oestrogen · GPER · Premenstrual syndrome $\cdot$ Hormone replacement therapy

\section{Introduction}

Mood disorders are one of the most common disorders in developed countries. The overall prevalence of anxiety disorders was estimated to be about $2 \%$ to $10 \%$, potentially reaching 20\% in the elderly (Lindesay et al. 1989; Lehtinen et al. 1990; Flint 1994). While gender differences in severe mental health disorders, such as schizophrenia or bipolar disorders, are hardly noticeable, women score markedly higher in the prevalence of depression and anxiety disorders. This difference manifests after puberty (for review, see Hayward and Sanborn 2002), indicating the importance of sexual hormones. Changes in mood throughout the menstrual cycle display strong inter-individual differences, with a subgroup of women experiencing severe premenstrual anxiety symptoms (Chisholm et al. 1990).

In line with alterations in anxiety during the menstrual cycle in human beings (Toufexis et al. 2006), alterations in anxietyrelated tests were also reported for female rodents (Frye et al. 2000; Marcondes et al. 2001; Morgan and Pfaff 2002). While anxiety levels appeared to be lower during late pro-oestrus and oestrus, indicators of increased anxiety were observed during late dioestrus/early pro-oestrus, the time of rising oestrogen in female mice and rats. It was suggested that these mood changes might be due to the anxiolytic effects of larger amounts of oestrogen, which are preceded by the anxiogenic effects of fluctuations in oestrogen levels (Toufexis et al. 2006). 
Constantly increased oestrogen $\left(\mathrm{E}_{2}\right)$ levels via $\mathrm{E}_{2}$ replacement therapy can improve mood conditions in menopausal women and younger women with low $\mathrm{E}_{2}$ levels. However, not all individuals respond favourably to $\mathrm{E}_{2}$. Under certain circumstances, women reported feeling even less anxiety when $E_{2}$ levels were low and/or stable, rather than rising (Walf and Frye 2006). Women suffering from premenstrual syndrome were frequently found in this group, which led to the hypothesis of individual sex steroid sensitivity (for review, see Backstrom et al. 2003).

Oestrogen exerts its effects through two classes of receptors, the nuclear receptors alpha $(\mathrm{ER} \alpha)$ and beta $(\mathrm{ER} \beta)$ and membrane-bound G-protein-coupled receptor(s), with the orphan receptor GPR30 being the most prominent candidate. While the anxiolytic effects of oestrogen treatment are mostly attributed to the nuclear receptor ER $\beta$ (Tetel and Pfaff 2010), the neurobiochemical background of the anxiogenic effects of low and fluctuating levels of oestrogen have only been marginally investigated so far.

The aim of this study was to identify which receptor(s) displays anxiogenic properties. This/these receptor(s) might represent candidates for being in imbalance with the anxiolytic ER $\beta$ in women who suffer from premenstrual syndrome or who respond negatively to oestrogen replacement therapy. Thus, either antagonists to this/these receptor(s) or ER $\beta$ specific agonists might provide novel treatment options, respectively.

\section{Material and methods}

\section{Animals}

Commercial C57B1/6 N mice (Charles River, Sulzfeld, Germany) were either used directly or bred for a maximum of three generations in our animal facility. Data obtained from the purchased animals were indistinguishable from those bred in our own facility. If bred and purchased animals were used within one experiment, equal distribution between groups was controlled. For breeding and maintenance, the mice were group housed with free access to food and water. The temperature was fixed at $23^{\circ} \mathrm{C}$ with $60 \%$ humidity and a $12 \mathrm{~h} \mathrm{light-}$ dark cycle (lights on 7 a.m. to 7 p.m.). Age and testingexperience-matched intact and ovariectomized mice at 3 to 8 months of age were used in all experiments. The ovariectomy procedure was performed on mice at the age of 3 months under anaesthesia initialized by ketamin and maintained by sevoflouran. The mice received a single dose of $2 \mathrm{mg} / \mathrm{kg}$ meloxicam for postsurgical analgesia. Testing started after 3 weeks of recovery. All procedures involving animals were approved by the Austrian Animal Experimentation Ethics Board in compliance with the European convention for the protection of vertebrate animals used for experimental and other scientific purposes, ETS no. 123. Every effort was taken to minimize the number of animals used.

Determination of oestrous stage

The oestrous stage was identified from vaginal smears based on the presence and proportion of round, nucleated epithelial cells, needle-like cornified (or keratinized) cells or leukocytes (Marcondes et al. 2002; Goldman et al. 2007). The smears were double analysed, natively and after GIEMSA staining. All animals were tested for normal cycling over a period of 2 weeks, ovariectomized animals were controlled for lack of cycling for 1 week starting 2 weeks after surgery. Only animals with normal cycling behaviour (or total lack in case of ovariectomized mice) were included into tests. After each anxiety test, oestrous stage was controlled and animals were sorted into three groups containing animals that were in metoestrus or early dioestrus (called the dioestrus group), late dioestrus or early pro-oestrus (called the pro-oestrus group) or oestrus (called the oestrus group). Late pro-oestrus usually occurred in the afternoon. In line with our testing time ( 9 a.m. to 1 p.m.), no animals in this stage were tested.

\section{Behavioural testing}

Unless stated otherwise, the mice were transferred to the ante-room of the testing facility $24 \mathrm{~h}$ before the commencement of experiments. The free access to food and water, the climate and the light-dark cycle were kept constant. The tests were performed between 9 a.m. and 1 p.m. All tests were video monitored and evaluated by an experimenter blinded to the pharmacological treatment of the animals. All animals were controlled for abnormal behaviour, intact reflexes and obvious health problems by giving them a "physical exam" (Karl et al. 2003) 2 weeks before testing. Tests were always performed following the sequence open field test, elevated plus maze and light dark test with 7 test free days between each test. The procedures for the open field, elevated plus maze and light-dark choice tests were performed as recently published (Wittmann et al. 2009) in accordance with the recommendations of EMPRESS (European Mouse Phenotyping Resource of Standardised Screens; http://empress.har.mrc.ac.uk).

In short, the open field arenas had a size of $50 \times 50 \mathrm{~cm}$ and were illuminated to $150 \mathrm{~lx}$. Mice were observed over $10 \mathrm{~min}$, measuring time, distance travelled and number of entries into three subfields: centre (central $16 \%$ of overall area), border ( $8 \mathrm{~cm}$ along walls) and intermediate.

The light-dark test was performed in the same arenas with a black box inserted, which covered $1 / 3$ of the area. Light was set to $400 \mathrm{~lx}$ and mice tested for 10 min measuring time, distance travelled and number of entries into the light compartment. 
The elevated plus maze test consisted of four arms, two closed (20 cm walls) and two open arms, each $50 \times 5 \mathrm{~cm}$ in size elevated about $80 \mathrm{~cm}$ above ground. Exploratory activity on the open arms was tested over $5 \mathrm{~min}$ at $180 \mathrm{~lx}$.

The forced swim test was performed in a single $15 \mathrm{~min}$ trial at a water temperature of $25^{\circ} \mathrm{C}$. Immobility, defined as no activity for at least $2 \mathrm{~s}$, was independently evaluated from video clips for the interval from the second to the sixth minute and for the final 4 min by two investigators blinded to the genotype and/or treatment of the animals.

The tail suspension test was performed in a single 6-min trial. Mice were elevated about $20 \mathrm{~cm}$ above a plate light to $150 \mathrm{~lx}$.

Basal activity and circadian rhythm of intact and ovariectomized mice was monitored in their home cages using the Infra-Mot system (TSE, Bad Homburg, Germany). Animals were observed for two dark-light cycles after an initial accommodation phase of several hours.

\section{Oestrogen receptor pharmacology}

The general oestrogen receptor agonist $\beta$-oestradiol, the specific oestrogen receptor $\alpha$ agonist 4,4',4"-(4-propyl$[1 H]$-pyrazole-1,3,5-triyl)trisphenol (PPT) (Stauffer et al. 2000) and the specific oestrogen receptor $\beta$ agonist 2,3-bis (4-hydroxyphenyl)-propionitrile (DPN) (Meyers et al. 2001) were purchased from Tocris Cookson (Bristol, UK). The specific agonist against the G-protein-coupled oestrogen receptor $($ GPER $=$ GPR30) 1-(4-(6-bromobenzo[1,3]dioxol5-yl)-3a,4,5,9b-tetrahydro-3H-cyclopenta[c]quinolin-8-yl)ethanone (G-1) (Bologa et al. 2006) was purchased from Calbiochem (VWR, Vienna, Austria). All drugs were dissolved in DMSO and subcutaneously injected $2 \mathrm{~h}$ or 2 and $24 \mathrm{~h}$ before testing in a total volume of $30 \mu \mathrm{l}$. The time points were chosen to simulate the situation in late dioestrus/ early pro-oestrus. The dosages were chosen according to recent studies on rodents (Lund et al. 2005). Assuming an even distribution of $\beta$-oestradiol due to its chemical nature, the doses we used yield concentrations of 0.1 to $1 \mu \mathrm{M}$ and therefore are on the lower end of the scale of doses used for in vivo testing (Lund et al. 2005; Rocha et al. 2005; Kocic et al. 2010; Intapad et al. 2011). This is in line with our intention to simulate the rising period of oestrogen and we assume mainly oestrogen receptor mediated effects. The DMSO and agonist treatments caused some mild signs of discomfort within the first few minutes after application, which were most probably due to the volume of about $30 \mu \mathrm{l}$ being subcutaneously injected into the inguinal region. In any case, a similar behaviour was observed in all animals after the subcutaneous saline injection. No differences in ambulation in the open field were observed between the animals injected with saline or DMSO. No tissue irritations were observed in this region when the mice were examined after the experiments.
Statistical analysis

Comparisons of more than two groups were performed using one-way ANOVA followed by the Bonferroni or Dunnett post-hoc tests, using Prism 5.0 (GraphPad Software Inc., La Jolla, CA); $P$ values of $<0.05$ were accepted as statistically significant. All data are given as mean $\pm \operatorname{SEM}(n)$.

\section{Results}

Intact female mice

\section{Anxiety-related behaviour}

Anxiety-like behaviour was tested in the elevated plus maze, light-dark choice tests and the open field test. Immediately after the tests, the stage of the oestrous cycle was determined from vaginal smears and the animals were grouped in relation to the oestrous stage for analysis (Fig. 1). The mice in the late dioestrus/early pro-oestrus group displayed a significant reduction in exploratory drive during the ovarian cycle as compared to the met-oestrus/early dioestrus group. This was reflected in all three parameters investigated: time spent on (reduced by $73 \%$ ), distance travelled on (reduced by $67 \%$ ) and number of entries (reduced by $38 \%$ ) onto the open arms of the elevated plus maze (Fig. 1a). In contrast, we observed no changes in overall activity (12.4 \pm 1.3 (18); $11.3 \pm 1.3$ (13); $10.8 \pm 1.2$ (16) entries onto the closed arms in met-oestrus/ early dioestrus, late dioestrus/early pro-oestrus, and oestrus, respectively). Decreased ambulation during the late dioestrus and early pro-oestrus phases also became evident in the lightdark choice test (Fig. 1b). The time spent in and the distance travelled in the illuminated area were both reduced by $64 \%$, while the number of entries were only reduced during the late dioestrous and early pro-oestrous phases of the ovarian cycle. No behavioural differences throughout the oestrous cycle were observed in the open field test (Fig. 1c).

\section{Stress-related behaviour}

Stress-related behaviour was tested in the forced swim and tail suspension tests. Evaluation in respect to oestrous stage revealed a 53\% reduction in immobility in late dioestrus and early pro-oestrus vs. met-oestrus and early dioestrus in the early phase (second to sixth minute) of the forced swim test (Fig. 1d), which most probably reflected increased anxiety levels in this group of animals. In the late phase (the eleventh to the fifteenth minute), no differences were observed between the different stages of the oestrous cycle (Fig. 1e). No differences in stress coping abilities were observed throughout the oestrous cycle in the tail suspension test (Fig. 1f). 


\section{A}

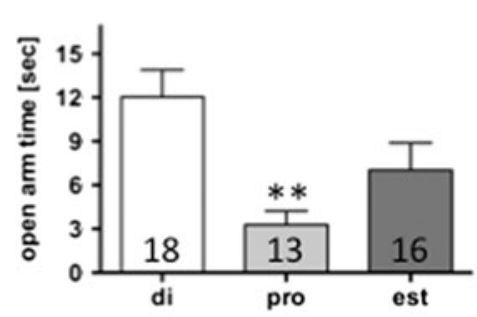

B

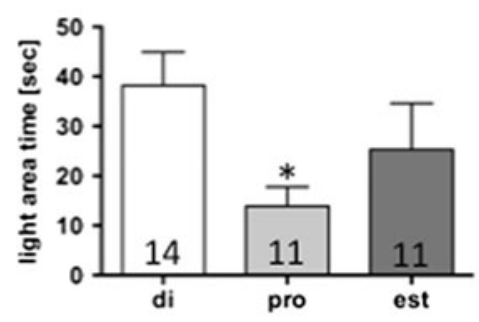

C

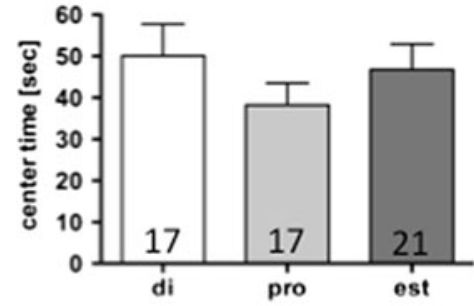

D

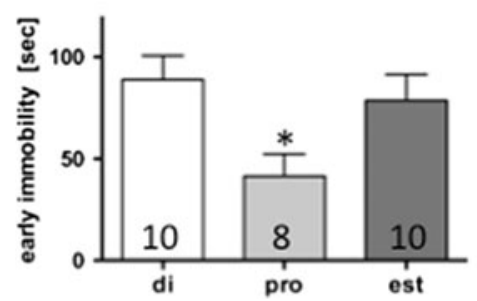

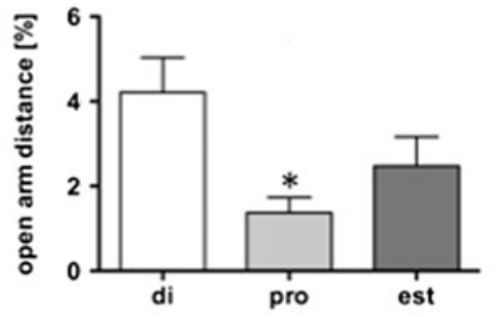
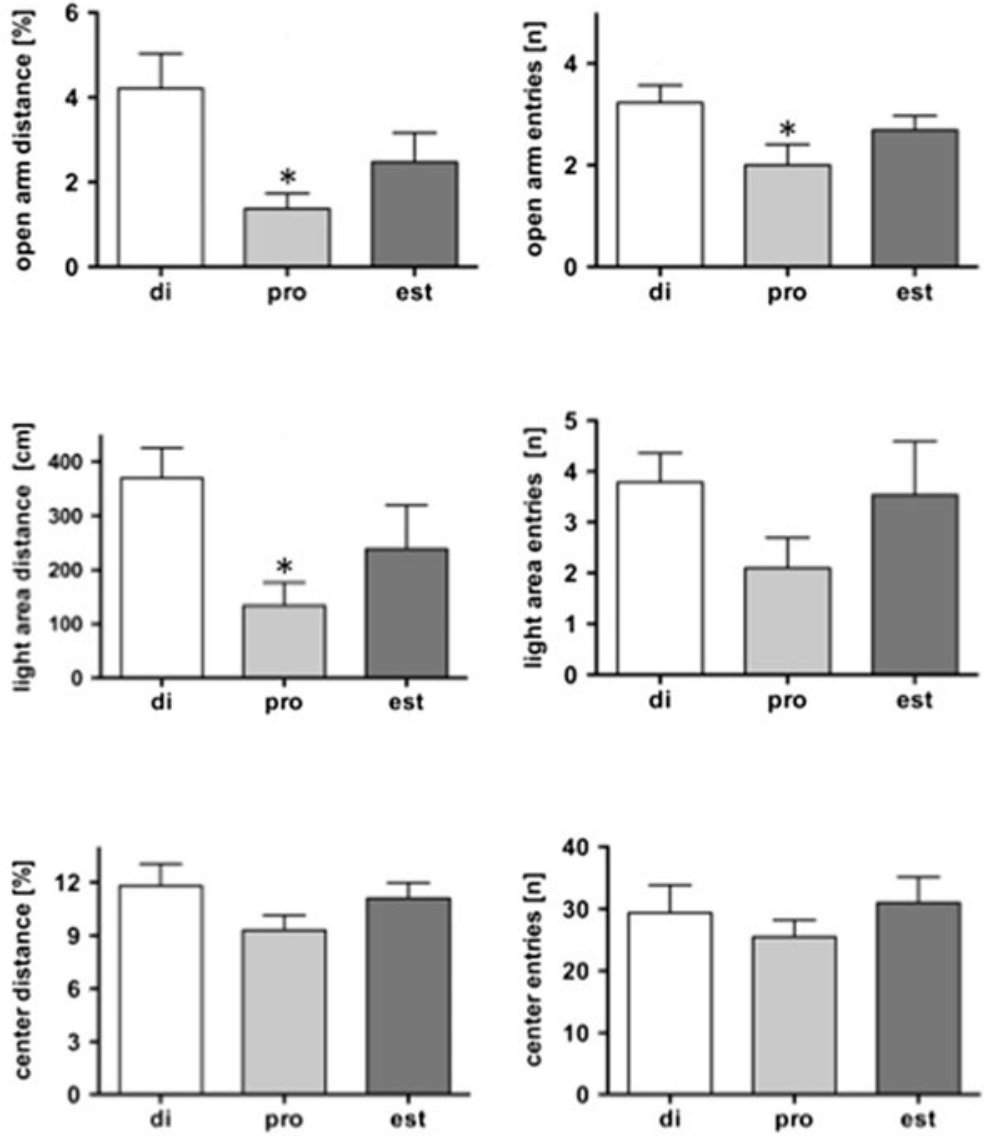

$\mathrm{E}$

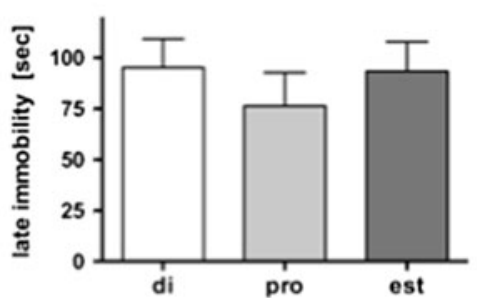

$\mathrm{F}$

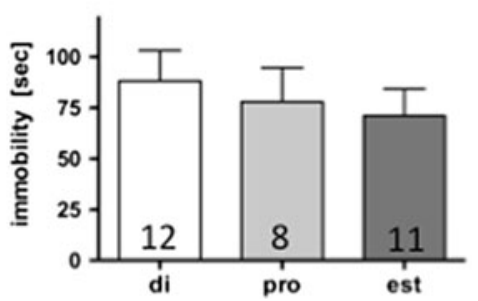

Fig. 1 Anxiety-related parameters were evaluated in the elevated plus maze (a), the light-dark choice test (b) and the open field test (c) in intact female $\mathrm{C} 57 \mathrm{Bl} / 6 \mathrm{~N}$ mice at different stages of the oestrous cycle. In the forced swim test, significant differences in immobility were only observed during the initial phase of the test (second to sixth minute; d),

\section{Ovariectomized female mice}

The intact female mice displayed strong inter-individual differences, which, at least partly, might have been due to the fluctuations in oestrogen levels during the short phases of late dioestrus and early pro-oestrus. The entire oestrous cycle only lasts 5-7 days, with mice spending only a few hours in early pro-oestrus. Therefore, we decided to switch to a hormonally more stable system: ovariectomized females. The ovariectomy but not in the late phase (11th to 15 th minute; e). No differences were observed in the tail suspension test (f). Numbers in the columns indicate the number of animals in the respective groups. $* P<0.05, * * P<0.01$ vs. di-group. di met-oestrus + early dioestrus, pro late di- + early pro-oestrus, oest oestrus, as assessed by vaginal smear analyses procedure was performed in female mice at the age of 3 months to allow normal development of the oestrogen receptors. Testing started after a recovery period of 3 weeks. During the last week before testing, vaginal smears were taken daily to ensure that the mice were no longer going through the cycle. The ovariectomized mice did not show any abnormal behaviour but they did display reduced motor activity in the home cage. Intact female mice travelled 61.066 \pm 12.068 (7) arbitrary activity counts over a $24 \mathrm{~h}$ period in their home cage. 
In contrast, ovariectomized mice only travelled $20.094 \pm 1.287$ (4) arbitrary activity counts over a $24-\mathrm{h}$ period, which was in the range measured for male mice (Wittmann et al. 2009).

\section{Effects of oestrogen treatment on anxiety-related behaviour}

In order to investigate whether or not anxiogenic-like behaviour in early pro-oestrus can be mimicked by a general oestrogen receptor agonist, $17 \beta$-oestradiol was applied $2 \mathrm{~h}$ prior to testing in two different doses $(0.025$ and $0.25 \mathrm{mg} / \mathrm{kg})$. This early time point and the low doses of $\beta$-oestradiol were chosen to simulate the early pro-oestrus phase of the cycle. Treatment with the lower dose of $\beta$-oestradiol significantly reduced the exploratory drive in the open field test (Fig. 2a). Thus, the time spent in and the entries onto the centre were reduced by $56 \%$, and the distance travelled in the centre was reduced by $48 \%$. In contrast, little influence was observed on behaviour in the elevated plus maze (Fig. 2b) and in the lightdark choice tests (Fig. 2c). It is noteworthy that no reduction in exploratory drive was observed after treatment with $0.25 \mathrm{mg} \beta$ oestradiol $/ \mathrm{kg}$ in the open field test, resulting in statistically significant differences between low and high $\beta$-oestradiol treatments (Fig. 2a). In the elevated plus maze, ambulation on the open arms appeared to be increased after treatment with $0.25 \mathrm{mg} \beta$-oestradiol $/ \mathrm{kg}$, also resulting in a statistically significant difference between low and high $\beta$-oestradiol treatments (Fig. 2b). Thus, the anxiolytic and anxiogenic effects induced by $\beta$-oestradiol are highly dependent on the dose applied and the testing paradigm. This could be due to overlapping effects of $\beta$-oestradiol mediated by different receptors. Therefore, we decided to address this question by using specific oestrogen receptor agonists.
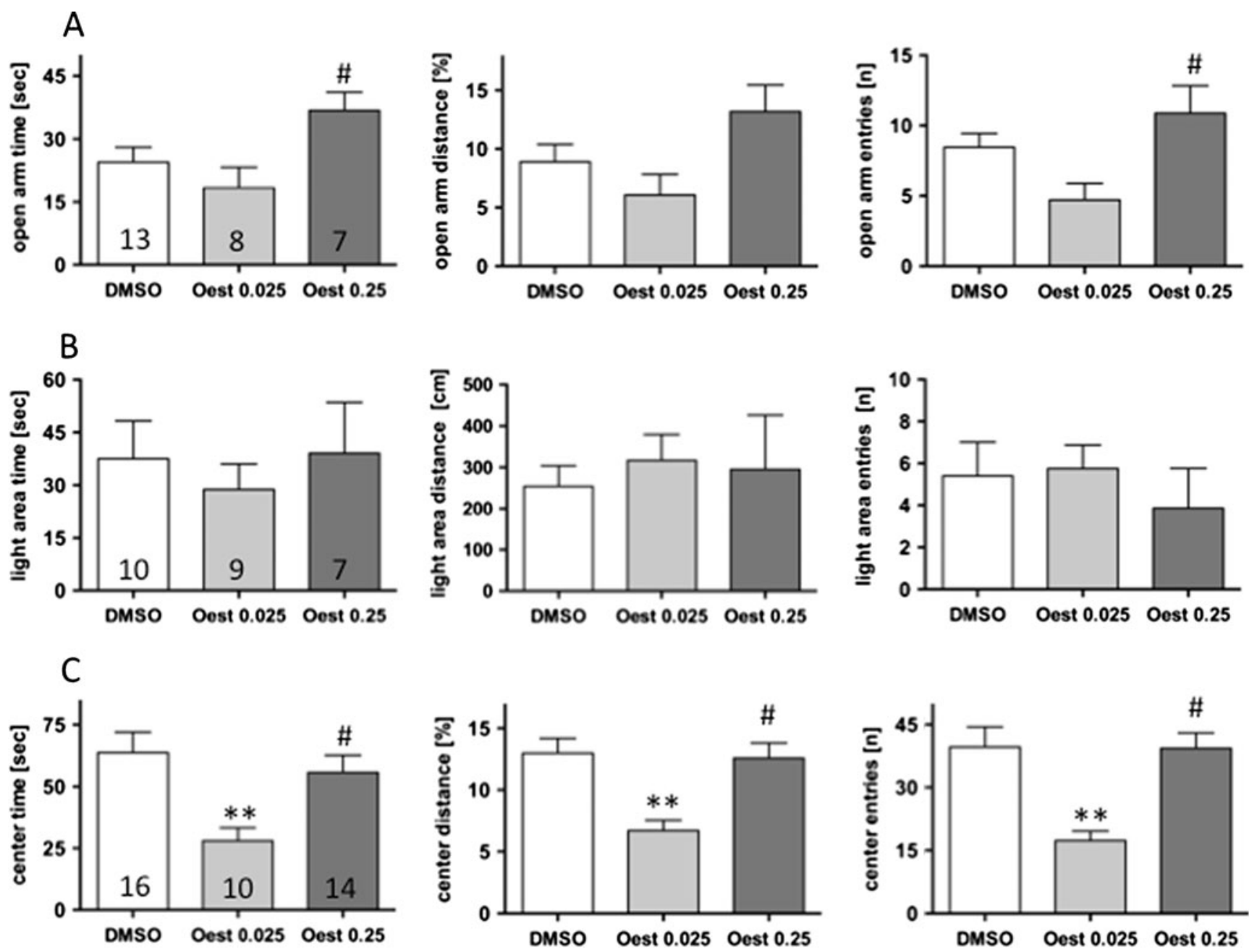

Fig. 2 Ovariectomized female mice were tested $2 \mathrm{~h}$ after treatment with $0.025 \mathrm{mg} \beta$-oestradiol $/ \mathrm{kg}$ (Oest 0.025 ), $0.25 \mathrm{mg} \beta$-oestradiol $/ \mathrm{kg}$ (Oest 0.25 ) or DMSO. Anxiety-related parameters were evaluated in the elevated plus maze (a) and the light-dark choice test (b), and the open field test (c). Numbers in the columns indicate the number of animals in the respective groups. ${ }^{*} P<0.05,{ }^{* *} P<0.01$ vs. DMSO; ${ }^{*} P \leq$ 0.05 vs. est low 
Pharmacology of the effects of $\beta$-oestradiol on anxiety-related behaviour

Agonists against the three presently known oestrogen receptors (PPT against ER $\alpha$, DPN against ER $\beta$ and G- 1 against GPR30; $1 \mathrm{mg} / \mathrm{kg}$ each) were given to ovariectomized female mice $2 \mathrm{~h}$ before testing. Mice treated with PPT or DPN did not differ from those treated with DMSO alone. A tendency towards increased exploration in the light-dark test was only observed after treatment with the ER $\beta$ agonist DPN. In contrast, G-1, the GPR30 agonist, produced strong anxiogenic effects in the elevated plus maze and open field tests (Fig. 3a, b) where, in the open field test, time spent in the centre was reduced by $67 \%$, distance travelled in the centre was reduced by $47 \%$, and the number of entries into the centre was reduced by $59 \%$ after G-1 treatment. In line with this, open arm time, distance and entries were reduced by $59 \%, 72 \%$, and $45 \%$, respectively. No significant alterations were observed in the light-dark choice tests after G-1 treatment.

Intact male mice

Anxiogenic effects of both $\beta$-oestradiol and G-1 were also observed in intact male mice, which displayed a markedly reduced exploratory drive after treatment with $\beta$-oestradiol or G-1 in all anxiety-related tests (Fig. 4). Beta-oestradiol significantly reduced the explorative behaviour on the open arms of the elevated plus maze for time and distance travelled by $37 \%$ and $43 \%$, respectively. Similarly, time and distance travelled in the light-dark choice tests were decreased by $48 \%$ each, after $\beta$-oestradiol application. Analysis of open field exploration did not reveal significant differences after $\beta$ oestradiol treatment. The application of G-1 induced strong anxiogenic effects. Thus, open arm time, distance travelled and entries onto the open arms were reduced by $60 \%$ and
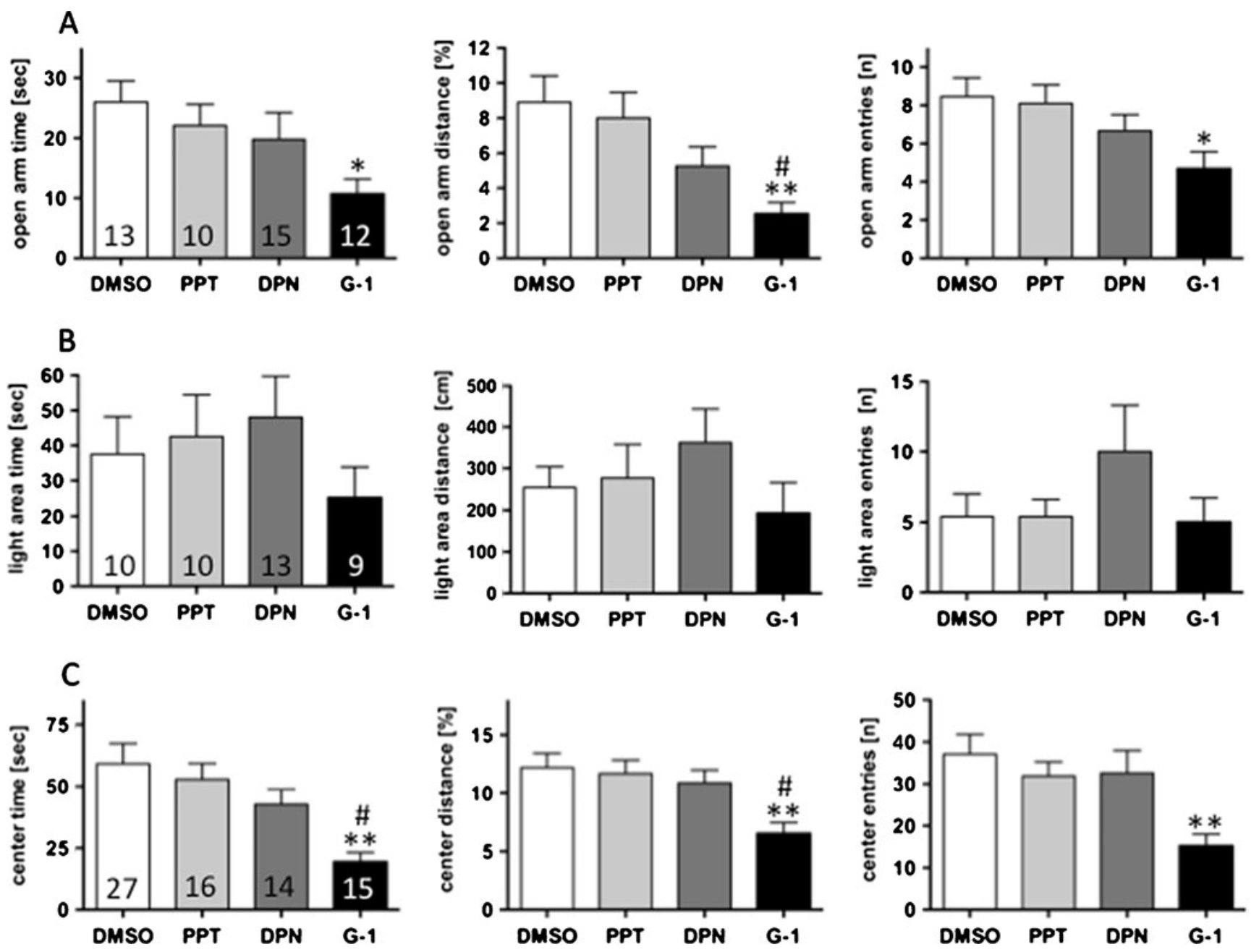

Fig. 3 In order to overcome problems of potentially overlapping actions of different receptors, ovariectomized female mice were tested $2 \mathrm{~h}$ after treatment with the ER $\alpha$ agonist PPT, the ER $\beta$ agonist DPN, the GPER agonist G-1 and DMSO. Anxiety-related parameters were evaluated in the elevated plus maze test (a), the light-dark choice test (b), and the open field (c). Numbers in the columns indicate the number of animals in the respective groups. ${ }^{*} P<0.05,{ }^{* *} P<0.01$ vs. DMSO; ${ }^{\#} P<0.05$ vs. PPT 


\section{A}
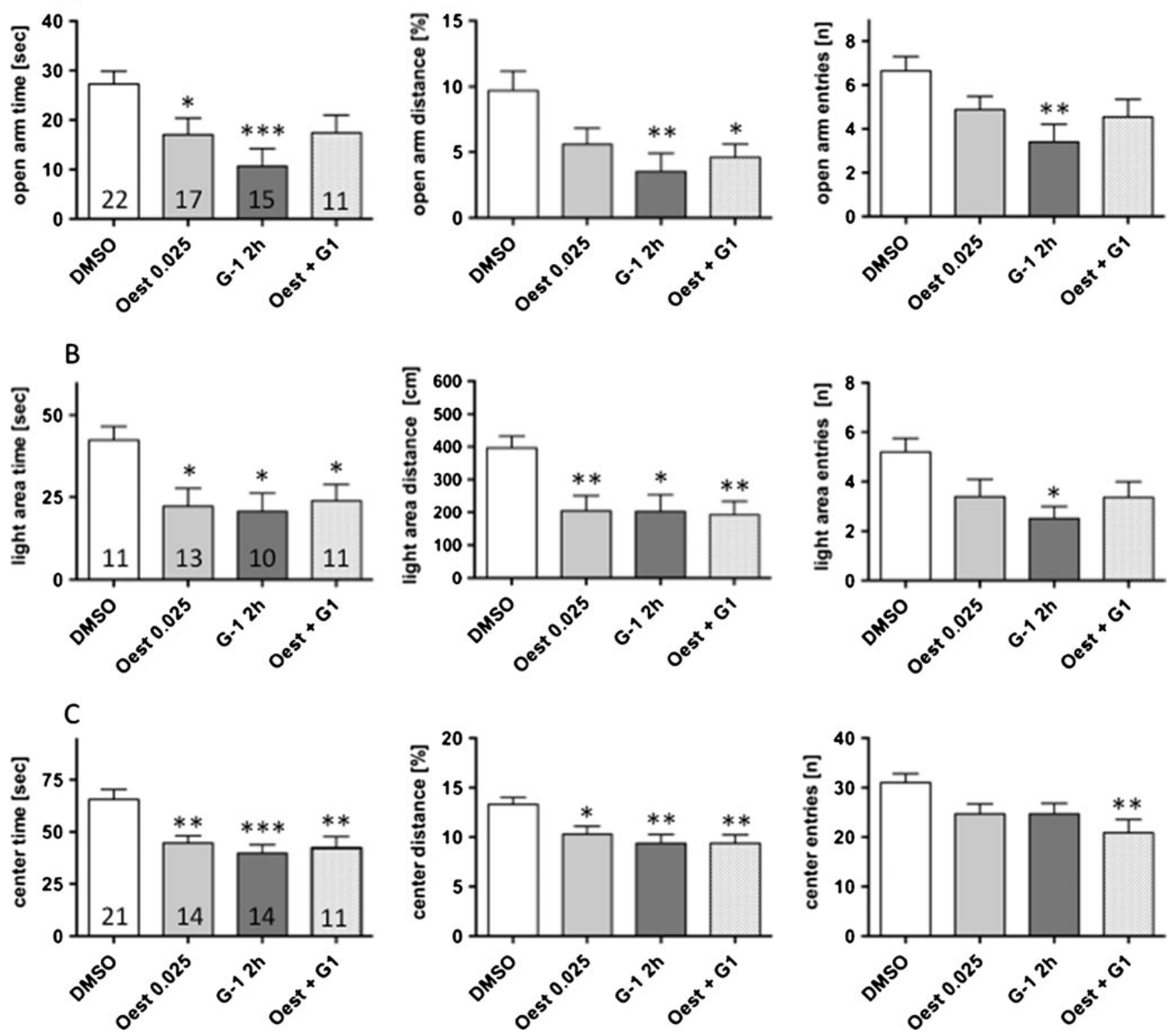

Fig. 4 Male mice are reported to display a similar pattern of oestrogen receptor expression as females, but a constantly low level of oestrogen expression. Therefore, we also analysed anxiety-related behaviour in male mice $2 \mathrm{~h}$ after treatment with $0.025 \mathrm{mg} \beta$-oestradiol $/ \mathrm{kg}$ or $1 \mathrm{mg} / \mathrm{kg} \mathrm{G}$ 1 (G-1 2 h). In addition, we included one group of animals that were treated with G-1 and b-oestradiol $2 \mathrm{~h}$ before testing (Oest $+\mathrm{G} 1)$. Their behaviour was analysed in the elevated plus maze (a), the light-dark choice (b), and the open field tests (c). Numbers in the columns indicate the number of animals in the respective groups. ${ }^{*} P<0.05,{ }^{* *} P<0.01$ vs. DMSO
$64 \%$, respectively. In the light-dark choice tests the exploratory parameters were decreased by $52 \%, 49 \%$, and $48 \%$ regarding time spent, distance travelled and entries into the light area, respectively. Combined application of $1 \mathrm{mg} / \mathrm{kg} \mathrm{G}-1$ and $0.025 \mathrm{mg} / \mathrm{kg}$ oestradiol did not result in a further increase in anxiogenic effects. The anxiogenic period in the oestrous cycle lasts only a few hours and question was, whether the anxiogenic receptors desensitize. To investigate this question, we applied $1 \mathrm{mg} / \mathrm{kg} \mathrm{G}-124$ and $2 \mathrm{~h}$ before testing. Results from these experiments did not differ markedly from those obtained after $2 \mathrm{~h}$ treatment. Thus mice spent $10.7 \pm 3.54 \mathrm{~s}$ (15) vs. $17.1 \pm 2.65 \mathrm{~s}(9)(p=0.2170)$; and travelled $3.52 \pm 1.37$ (15) vs. $7.4 \pm 1.7 \%$ (9) ( $p=0.0925)$; on the open arms (in $3.4 \pm 0.81$ (15) vs. $2.3 \pm 0.88$ entries (9); $p=0.3886) 2 \mathrm{~h}$ and $2+24 \mathrm{~h}$ after treatment, respectively. In the light-dark test, $20.7 \pm 5.54 \mathrm{~s} \mathrm{(10)}$ vs. $12.2 \pm 5.22 \mathrm{~s} \mathrm{(9)}(p=0.2826)$; and travelled $2.0 \pm 0.52(10)$ vs. $1.1 \pm 0.47 \mathrm{~m}$ (9) $(p=0.2201)$; on the open arms (in $2.5 \pm$ $0.50(10)$ vs. $1.7 \pm 0.73$ entries (9); $p=0.2638) 2 \mathrm{~h}$ and $2+24 \mathrm{~h}$ after treatment, respectively. Exploration of the centre area of the open field was also comparable between the two treatment regimens $(39.8 \pm 3.98 \mathrm{~s}(14)$ vs. $48.8 \pm 6.30 \mathrm{~s}(9) ; p=0.2166$; $9,4 \pm 0.91$ (14) vs. $9.8 \pm 1.82 \%$ distance (9); $p=0.7845$; in $25 \pm$ 
2.13 (14) vs. $29 \pm 3.04$ entries (9); $p=0.2791 ; 2 \mathrm{~h}$ and $2+24 \mathrm{~h}$ after treatment, respectively). In line with intact females in the late dioestrus and early pro-oestrus stages of the ovarian cycle anxiety-like behaviour was clearly expressed in the elevated plus maze (Figs. 1a and 4a) and light-dark choice tests (Figs. 1b and 4b), but less so in the open field test (Figs. 1c and $4 \mathrm{c}$ ). The overall activity in these tests appeared to be unchanged. The mice travelled $1.8 \pm 0.09 \mathrm{~m}$ (16); $1.6 \pm$ $0.07 \mathrm{~m} \mathrm{(9)} ; 1.6 \pm 0.12 \mathrm{~m} \mathrm{(14)}$ and $1.9 \pm 0.09 \mathrm{~m}$ (9) after treatment with DMSO, $\beta$-oestradiol and G-1 $(2$ and $2+24 \mathrm{~h}$ before testing), respectively, in the elevated plus maze and $4.0 \pm$ $0.12 \mathrm{~m}$ (14); $3.7 \pm 0.10 \mathrm{~m}(10) ; 4.8 \pm 0.98 \mathrm{~m}$ (14) and $4.6 \pm$ $0.14 \mathrm{~m}(9)$ in the open field, respectively.

\section{Discussion}

During the menstrual cycle in humans and the oestrous cycle in rodents the serum levels of the hormones oestradiol, progesterone and luteinizing hormone vary in a rhythmic pattern (Goldman et al. 2007). Oestradiol rises in late dioestrus and declines throughout late pro-oestrus, whereas progesterone and luteinizing hormone start to rise in late pro-oestrus. As we observed a reduced exploratory drive in intact female mice during late dioestrus and early pro-oestrus, oestradiol represents the most probable candidate involved in this effect. Indeed, the reduced exploratory drive could be mimicked in ovariectomized female and intact male mice shortly after the application of the low dose of $\beta$-oestradiol. The fact that a higher dose of $\beta$-oestradiol induced contrary effects in ovariectomized female mice suggests that distinct oestrogen receptor populations may induce counteracting anxiogenic or anxiolytic effects. This is in line with the assumption that stable and high concentrations of oestrogen are anxiolytic, whereas fluctuating and low levels of oestrogen often cause anxiogenic effects (Toufexis et al. 2006). Anxiogenic effects of oestrogen have been reported in female rats treated with $10 \mu \mathrm{g} / \mathrm{kg}$ oestradiol benzoate $3 \mathrm{~h}$ before testing (Mora et al. 1996). Anxiolytic effects of oestrogen were reported after higher doses of $\beta$-oestradiol (of up to $250 \mu \mathrm{g} / \mathrm{kg}$ ) over prolonged periods (i.e., several days). The ER $\beta$ was identified as a primary candidate for mediating anxiolytic effects (Lund et al. 2005), while ER $\alpha$ was apparently less important in emotional control (for review, see Tetel and Pfaff 2010). Functional investigations into GPR30, which was recently proposed as an oestrogen receptor and therefore also named GPER, are rare (for review, see Mizukami 2009), and no information on the influence of GPR30 on anxiety is currently available.

In order to overcome the potential problems of counteracting oestrogen receptor populations we applied specific agonists against $\mathrm{ER} \alpha, \mathrm{ER} \beta$ and GPR30. Agonists against the nuclear oestrogen receptors did not significantly alter the behaviour of mice at the dosage and time interval applied. These receptors mainly mediate their effects through the regulation of gene expression, while fast effects of oestrogen are frequently thought to be mediated by at least one membrane-bound receptor using alternative signalling pathways. In contrast to the nuclear receptor agonists, the GPR30 agonist G-1 caused anxiogenic effects in ovariectomized female WT mice. Anxiogenic effects of GPR30 stimulation were also reproduced in male mice, which express this receptor in a similar manner to female mice (Hazell et al. 2009).

In the mouse, GPR30 is expressed in several nuclei involved in emotional control, such as the paraventricular hypothalamic nucleus, septal complex nuclei, hippocampal nuclei and the supraoptic nucleus, for example (Hazell et al. 2009). Moreover, proposed functions of GPR 30 such as the release of $\mathrm{Ca}^{2+}$ from internal stores (for review, see Hazell et al. 2009) may influence neuronal functions or facilitate the release of neuropeptides. Of potential functional interest is a recent study, which suggested that GPR30 is highly expressed in neurons of the paraventricular hypothalamic nucleus (PVN) of rats, where it is involved in the attenuation of 5- $\mathrm{HT}_{1 \mathrm{~A}}$ receptor signalling (Xu et al. 2009). On the other hand, there is an ongoing discussion about whether or not GPR30 is indeed an oestrogen receptor; also, several controversies on the functions of GPR30 exist (for review, see Langer et al. 2010). Our data support the idea of GPR30 as a mediator of oestrogen effects. Moreover, for the first time, we provide evidence to show that the activation of GPR30 causes anxiogenic effects. These effects could be also observed after prolonged stimulation of GPR30, suggesting that the short-lived period of higher anxiety is not terminated by desensitisation of GPR30, but the anxiolytic effects mediated through other receptors. This may also the neurobiological background of the discrepancy between high doses of $\beta$ oestradiol as a general oestrogen receptor agonist and the G-1 as a specific GPR30 agonist. Most probable candidates for overlaying anxiogenic effects are genomic actions mediated via $\mathrm{ER} \beta$ (Lund et al. 2005).

Individual sex steroid sensitivity was hypothesized as being an explanation for the severe mood changes during the oestrous cycle and the aversive emotional side effects of oestrogen replacement therapy in a subpopulation of women (Backstrom et al. 2003). The anxiolytic effects mediated by ER $\beta$ would be counteracted by a so far unknown mediator of anxiogenic effects of oestrogen. Our data suggest that GPR30 could represent this counteracting partner and an imbalance between ER $\beta$ and GPR30 may be the neurobiochemical background of aversive emotional side effects of oestrogen replacement therapy. Women from this group often report that they feel better at low oestrogen levels, which would make sense considering the approximately 10 times lower affinity of GPR30 to $\beta$-oestradiol than the 
nuclear receptors (Cornil et al. 2006). These women also reported feeling worse under fluctuations of $\mathrm{E}_{2}$ levels, which may reflect the faster transmission of effects by Gprotein coupled receptors compared to nuclear receptors, which mostly mediate their effect through transcriptional regulation. In any case, our data together with data published on the anxiolytic effects of ER $\beta$ activation suggest that the aversive effects of oestrogen therapies may be overcome, at least in part, by avoiding the stimulation of GPR30 during replacement therapy (i.e., through the development of ER $\beta$ specific agonists).

Acknowledgments The authors thank Mrs I. Kapeller and Mrs C. Stichlberger for their excellent technical assistance. This work was supported by the Austrian Science Fund (P20107-B05) and the Dr Legerlotz Fund.

Conflicts of interest The authors state that they have no conflicts of interest to declare.

Open Access This article is distributed under the terms of the Creative Commons Attribution Noncommercial License which permits any noncommercial use, distribution, and reproduction in any medium, provided the original author(s) and source are credited.

\section{References}

Backstrom T, Andreen L, Birzniece V, Bjorn I, Johansson IM, Nordenstam-Haghjo M, Nyberg S, Sundstrom-Poromaa I, Wahlstrom G, Wang M, Zhu D (2003) The role of hormones and hormonal treatments in premenstrual syndrome. CNS Drugs 17:325-342

Bologa CG, Revankar CM, Young SM, Edwards BS, Arterburn JB, Kiselyov AS, Parker MA, Tkachenko SE, Savchuck NP, Sklar LA, Oprea TI, Prossnitz ER (2006) Virtual and biomolecular screening converge on a selective agonist for GPR30. Nat Chem Biol 2:207212

Chisholm G, Jung SO, Cumming CE, Fox EE, Cumming DC (1990) Premenstrual anxiety and depression: comparison of objective psychological tests with a retrospective questionnaire. Acta Psychiatr Scand 81:52-57

Cornil CA, Ball GF, Balthazart J (2006) Functional significance of the rapid regulation of brain estrogen action: where do the estrogens come from? Brain Res 1126:2-26

Flint AJ (1994) Epidemiology and comorbidity of anxiety disorders in the elderly. Am J Psychiatry 151:640-649

Frye CA, Petralia SM, Rhodes ME (2000) Estrous cycle and sex differences in performance on anxiety tasks coincide with increases in hippocampal progesterone and 3alpha,5alpha-THP. Pharmacol Biochem Behav 67:587-596

Goldman JM, Murr AS, Cooper RL (2007) The rodent estrous cycle: characterization of vaginal cytology and its utility in toxicological studies. Birth Defects Res B Dev Reprod Toxicol 80:84-97

Hayward C, Sanborn K (2002) Puberty and the emergence of gender differences in psychopathology. J Adolesc Health 30:49-58

Hazell GG, Yao ST, Roper JA, Prossnitz ER, O'Carroll AM, Lolait SJ (2009) Localisation of GPR30, a novel G protein-coupled oestrogen receptor, suggests multiple functions in rodent brain and peripheral tissues. J Endocrinol 202:223-236
Intapad S, Dimitropoulou C, Snead C, Piyachaturawat P, J DC (2011) Regulation of asthmatic airway relaxation by estrogen and heat shock protein 90. J Cell Physiol. doi:10.1002/JCP.23045

Karl T, Pabst R, von Horsten S (2003) Behavioral phenotyping of mice in pharmacological and toxicological research. Exp Toxicol Pathol 55:69-83

Kocic I, Szczepanska R, Wapniarska I (2010) Estrogen-induced relaxation of the rat tail artery is attenuated in rats with pulmonary hypertension. Pharmacol Rep 62:95-99

Langer G, Bader B, Meoli L, Isensee J, Delbeck M, Noppinger PR, Otto C (2010) A critical review of fundamental controversies in the field of GPR30 research. Steroids 75:603-610

Lehtinen V, Joukamaa M, Lahtela K, Raitasalo R, Jyrkinen E, Maatela J, Aromaa A (1990) Prevalence of mental disorders among adults in Finland: basic results from the Mini Finland Health Survey. Acta Psychiatr Scand 81:418-425

Lindesay J, Briggs K, Murphy E (1989) The Guy's/Age Concern survey. Prevalence rates of cognitive impairment, depression and anxiety in an urban elderly community. Br J Psychiatry 155:317-329

Lund TD, Rovis T, Chung WC, Handa RJ (2005) Novel actions of estrogen receptor-beta on anxiety-related behaviors. Endocrinology 146:797-807

Marcondes FK, Miguel KJ, Melo LL, Spadari-Bratfisch RC (2001) Estrous cycle influences the response of female rats in the elevated plus-maze test. Physiol Behav 74:435-440

Marcondes FK, Bianchi FJ, Tanno AP (2002) Determination of the estrous cycle phases of rats: some helpful considerations. Braz J Biol 62:609-614

Meyers MJ, Sun J, Carlson KE, Marriner GA, Katzenellenbogen BS, Katzenellenbogen JA (2001) Estrogen receptor-beta potencyselective ligands: structure-activity relationship studies of diarylpropionitriles and their acetylene and polar analogues. J Med Chem 44:4230-4251

Mizukami, Y. (2009) In vivo functions of GPR30/GPER-1, a membrane receptor for estrogen: from discovery to functions in vivo. Endocr $\mathrm{J}$

Mora S, Dussaubat N, Diaz-Veliz G (1996) Effects of the estrous cycle and ovarian hormones on behavioral indices of anxiety in female rats. Psychoneuroendocrinology 21:609-620

Morgan MA, Pfaff DW (2002) Estrogen's effects on activity, anxiety, and fear in two mouse strains. Behav Brain Res 132:85-93

Rocha BA, Fleischer R, Schaeffer JM, Rohrer SP, Hickey GJ (2005) 17 Beta-estradiol-induced antidepressant-like effect in the forced swim test is absent in estrogen receptor-beta knockout (BERKO) mice. Psychopharmacology (Berl) 179:637-643

Stauffer SR, Coletta CJ, Tedesco R, Nishiguchi G, Carlson K, Sun J, Katzenellenbogen BS, Katzenellenbogen JA (2000) Pyrazole ligands: structure-affinity/activity relationships and estrogen receptor-alpha-selective agonists. J Med Chem 43:4934-4947

Tetel MJ, Pfaff DW (2010) Contributions of estrogen receptor-alpha and estrogen receptor-beta to the regulation of behavior. Biochim Biophys Acta

Toufexis DJ, Myers KM, Davis M (2006) The effect of gonadal hormones and gender on anxiety and emotional learning. Horm Behav 50:539-549

Walf AA, Frye CA (2006) A review and update of mechanisms of estrogen in the hippocampus and amygdala for anxiety and depression behavior. Neuropsychopharmacology 31:1097-1111

Wittmann W, Schunk E, Rosskothen I, Gaburro S, Singewald N, Herzog H, Schwarzer C (2009) Prodynorphin-derived peptides are critical modulators of anxiety and regulate neurochemistry and corticosterone. Neuropsychopharmacology 34:775-785

Xu H, Qin S, Carrasco GA, Dai Y, Filardo EJ, Prossnitz ER, Battaglia G, Doncarlos LL, Muma NA (2009) Extra-nuclear estrogen receptor GPR30 regulates serotonin function in rat hypothalamus. Neuroscience 158:1599-1607 